\title{
On Deregulated Power System AGC with Solar Power
}

\author{
D. Teresa \\ Velagapudi Ramakrishna Siddhartha Engineering \\ College, Kanuru, Andhra Pradesh, India
}

\author{
M. S. Krishnarayalu \\ Velagapudi Ramakrishna Siddhartha Engineering \\ College, Kanuru, Andhra Pradesh, India
}

\begin{abstract}
Deregulated power system with multiple varieties of generations is the order of the day. In a power system, load varies continuously therefore frequency changes continuously. Automatic Generation Control (AGC) is used in the power system for balancing the generation and demand and control the changes in tie-line powers within the allowable limits by maintaining rated frequency. Solar power is nowadays very popular renewable energy in India and world. Many power deficit states in India have become power surplus states using it along with conventional thermal power. Benefits of deregulation such as improved efficiency, customer friendly services and lower prices for consumers are well known. Accordingly a two-area deregulated system is considered for investigation of AGC. Primary controllers like governors will not eliminate steady state errors which may not satisfy the constraints of power system. For better AGC responses, different secondary controllers like Integral, PID, PI-PD controllers are used for a two area deregulated power system consisting of reheat thermal, solar thermal and solar photovoltaic units. Here Integral, PID and PI-PD controllers are tuned by Particle Swarm Optimization (PSO) approach. The resulting deregulated power system is simulated and analyzed using MATLAB Simulink software to propose a good secondary controller.
\end{abstract}

\section{General Terms}

$\begin{array}{ll}\text { AGC } & \text { Automatic Generation Control } \\ \text { ACE } & \text { Area Control Error } \\ \Delta \mathrm{F}_{\mathrm{i}} & \text { Frequency deviation } \\ \Delta \mathrm{PTie}_{\mathrm{i}} & \text { Deviation in net tie-line power } \\ \mathrm{K}_{\mathrm{st}} & \text { Solar Thermal Model Gain } \\ \mathrm{K}_{\mathrm{s}-\mathrm{pv}} & \text { Solar Photovoltaic Model Gain } \\ \mathrm{GENCO} & \text { Generation Company } \\ \text { DISCO } & \text { Distribution Company } \\ \text { TRANSCO } & \text { Transmission Company } \\ \text { ISO } & \text { Independent Sys tem Operator } \\ & \\ \text { PX } & \text { Power Exchanger } \\ \text { RESCO } & \text { Retail Energy Service Company } \\ \text { MCP } & \text { Market Clearing Price } \\ \text { PID } & \text { Proportional Integral Derivative } \\ \text { PI-PD } & \text { Proportional } \\ & \text { Proportional Derivative Integral } \\ \text { ISE } & \text { Integral Square Error } \\ \text { IAE } & \text { Integral Absolute Error } \\ \text { ITSE } & \text { Integral Time Square Error } \\ \text { ITAE } & \text { Integral Time Absolute Error }\end{array}$

\section{Keywords}

Automatic generation control, Particle swarm optimization, Frequency error, Multi area power system, PID controller, PIPD controller, Tie line power deviation.

\section{INTRODUCTION}

In a power system, Automatic generation control (AGC) provides stable operations predominantly. The information about AGC and its different aspects are explained in [1-2]. System stability mainly depends on the nominal values of tieline power and frequency. An unstable operation may occur when there are sudden variations of load in any area and it results in the deviations in both the frequency and tie line powers. Reducing the value of Area control error (ACE) to zero is the responsibility of an AGC for the allowable limits of frequency and tie line powers.

In the world, the power utilities are currently experiencing deregulation process and operation. Competition in the power system utilities results in increase in industries efficiency and the cost of the power will be reduced. The restructured rules are set up by the government to control the electrical power industry and to provide economic stimulants. All these rules are known as deregulation. Deregulated power system is having GENCOs, DISCOs, TRANSCOs, ISO and other ancillary services. Maintenance of system reliability and security are the most challenging issues in the deregulation system. The DISCO participation matrix (DPM) and GENCO participation matrix (GPM) are presented in [5]. In [6], autonomous hybrid generation system consisting of solar photovoltaic [7], solar thermal system, wind turbine generator, battery storage system, diesel generator, aqua electrolyzer and fuel cell is used for the simulation.

For the reliable and effective interconnected power systems secondary controllers such as PID, PI-PD [8] and ADRC [13] are used for automatic generation control. There are many techniques for tuning these controllers such as Zeigler Nichols (ZN), Trial and error, Particle swarm optimization (PSO) [6], [10]-[11], [14], Fuzzy logic (FL) [4], Artificial neural network (ANN) [12] and Genetic algorithm (GA) [3] \& [12], differential evolution [3] methods.

\section{DEREGULATED POWER SYSTEM}

In deregulated system, cost of the electrical energy reduces and drives the industry in efficient way. New entities of deregulated system are GENCOs, DISCOs, TRANSCOs, PX, ISO, RESCOs and customers are shown in Fig 1. GENCOs are the generating units which produce the power and DISCOs are distribution companies which have the main objective of buying the power from the spot market or from the GENCOs directly and supply to the customers. TRANSCOs are transmitting companies which transmit power from GENCOs to the customers. Independent system operator (ISO) is the one which will give the reliability, security of the system. This unit does not participate in any type of transactions among GENCOs, DISCOs and TRANSCOs. Power Exchange (PX) updates the Market clearing price (MCP) continuously. MCP is the present price at which the transactions are carried out. Retail Energy Service Companies (RESCOs) are retailers who buy the 
electrical power from the GENCOs and sell directly to the consumers.

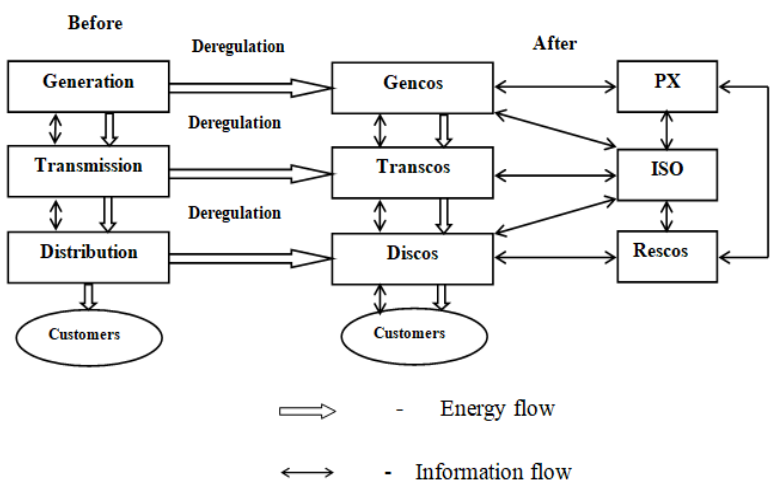

Fig. 1: Basic structure of deregulated power system

In deregulation system, the first step is division of generation from distribution and transmission. There are three different cases in the deregulated power system namely base, bilateral transaction and contract violation cases. Contract made between GENCOs and DISCOs depends upon the electricity requirement and a DISCO can contract with any of the GENCOs present in the system. These types of contracts are called as bilateral transactions. In base case, GENCOs and DISCOs of the corresponding area participate in power generation as per the load. The more amount of power demanded by the DISCO than contract in the contract violation case. Contract participation factor (cpf) is the factor that establishes how DISCO contracts to a GENCO. DISCO Participation Matrix (DPM) is one of the matrix which gives information about how all the DISCOs contracted with all the GENCOs in the system. In DPM, row represents the number of GENCOs and column represents the DISCOs in the power system. Every value in the matrix is a fraction of power demand that GENCO can contribute to a particular DISCO [5]. The values are represented as follows.

Steady state power flow on the tie-line power

$\triangle$ Ptie12,scheduled $=$ (DISCOs demand in area2 from GENCOs in area1)- (DISCOs demand in area1 from GENCOs in area2)

where, $\Delta$ Ptie-12,error $=\Delta$ Ptie1-2, actual $-\Delta$ Ptie1-2, scheduled

The error in the tie-line powers represented as

$$
\begin{aligned}
& \mathrm{e}_{1}(\mathrm{t})=\mathrm{ACE}_{1}=\mathrm{B}_{1} \Delta \mathrm{f}_{1}+\Delta \text { Ptie1-2, error } \\
& \mathrm{e}_{2}(\mathrm{t})=\mathrm{ACE}_{2}=\mathrm{B}_{2} \Delta \mathrm{f}_{2}+\Delta \text { Ptie2-1, error }
\end{aligned}
$$

$\Delta$ Ptie-2-1,error $=\alpha_{12} \Delta$ Ptie1-2,error

where $\alpha_{12}=-\frac{\operatorname{Pr} 1}{\operatorname{Pr} 2} ; P_{\mathrm{r} 1}$ and $\mathrm{P}_{\mathrm{r} 2}$ are the rated powers of area1and area-2.

Thus, ACE2 $=\mathrm{B} 2 \Delta \mathrm{f} 2+\alpha 12 \Delta$ Ptie1-2, error

Contract participation factor

$$
\mathrm{cpf}_{\mathrm{ij}}=\frac{\text { Power contribution of }^{\text {th }} \text { Genco to } \mathrm{j}^{\text {th }} \text { Disco }}{\mathrm{j}^{\text {th }} \text { Disco total power demand }}
$$

For two area power system there are two DISCOs and GENCOs in each area and DPM will be represented as

$$
D P M=\left[\begin{array}{ccccc}
c p f_{11} & c p f_{12} & \mathrm{~L} & \mathrm{~L} & c p f_{1 j} \\
c p f_{21} & c p f_{22} & \mathrm{~L} & \mathrm{~L} & c p f_{2 j} \\
\mathrm{M}^{2} & \mathrm{M} & \mathrm{O} & \mathrm{O} & \mathrm{M} \\
\mathrm{M} & \mathrm{M} & \mathrm{O} & \mathrm{O} & \mathrm{M} \\
c p f_{i 1} & c p f_{i 2} & \mathrm{~L} & \mathrm{~L} & c p f_{i j}
\end{array}\right]
$$

Generation participation matrix (GPM) is the matrix that distributes the ACE among GENCOs that are present in the system. In the GPM matrix every factor is nothing but the area participation factor (apf). In an area, sum of the apfs should be equal to one and the matrix will be

$$
G P M=\left[\begin{array}{ccccc}
\operatorname{apf}_{11} & \operatorname{apf}_{12} & \mathrm{~L} & \mathrm{~L} & \operatorname{apf}_{1 n} \\
\operatorname{apf}_{21} & \operatorname{apf}_{22} & \mathrm{~L} & \mathrm{~L} & \operatorname{apf}_{2 n} \\
\mathrm{M} & \mathrm{M} & \mathrm{O} & \mathrm{O} & \mathrm{M} \\
\mathrm{M} & \mathrm{M} & \mathrm{O} & \mathrm{O} & \mathrm{M} \\
\operatorname{apf}_{m 1} & \operatorname{apf}_{m 2} & \mathrm{~L} & \mathrm{~L} & \operatorname{apf}_{m n}
\end{array}\right]
$$

$\mathrm{m}=$ number of areas, $\mathrm{n}=$ number of sources

By considering all these matrices, modeling of AGC in a deregulated system can be done by using different controllers.

\section{SYSTEM INVESTIGATED}

The proposed work of two area power system consists of thermal and solar units in both areas. Each area consists of two GENCOs and two DISCOs. In thermal unit consists of governor, turbine and a reheat system. The solar unit consists of Solar module, governor, turbine and stfuldture of the deregulated power system is used as investigation is shown in the Fig. 2.

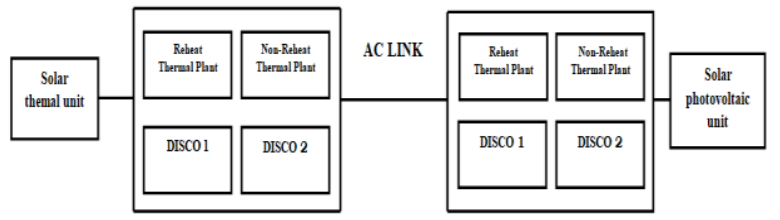

Fig. 2 Two area deregulated power system

The general diagram of AGC scheme including both solar thermal and solar photovoltaic system for an $\mathrm{i}^{\text {th }}$ area is shown in Fig. 3. Under deregulation Fig. 4 shows different components of two area power system and their transfer functions like governor, turbine - reheat, non-reheat and solar plants. Here, $T_{g}$ is the governor time constant, $T_{t}$ defines the turbine time constant, $K_{r}$ denotes the reheat system gain. $T_{r}$ stands for time constant for reheat system, $K_{p}$ represents gain of the power system, $T_{p}$ shows the power system time constant. $\mathrm{K}_{\mathrm{st}}$ and $\mathrm{T}_{\mathrm{st}}$ are gain and time constant for the solar thermal unit and $\mathrm{K}_{\mathrm{s}-\mathrm{pv}}$ and $\mathrm{T}_{\mathrm{s}-\mathrm{pv}}$ are the gain and time constant of solar photovoltaic system. 


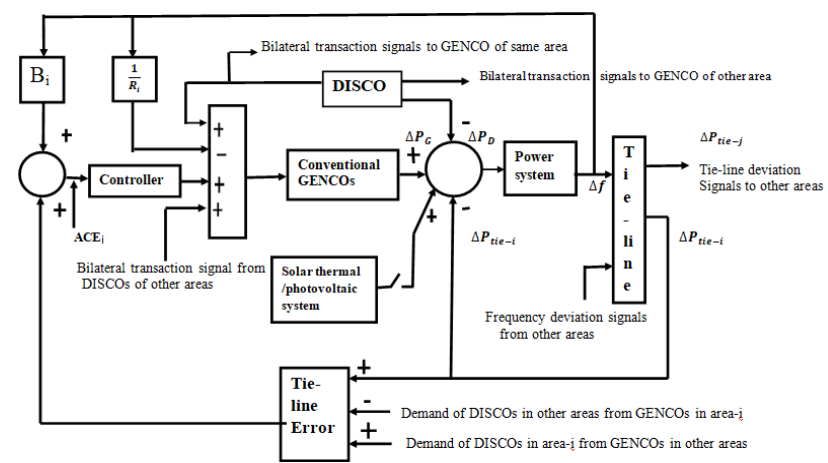

Fig.3 Block diagram for AGC of area-i

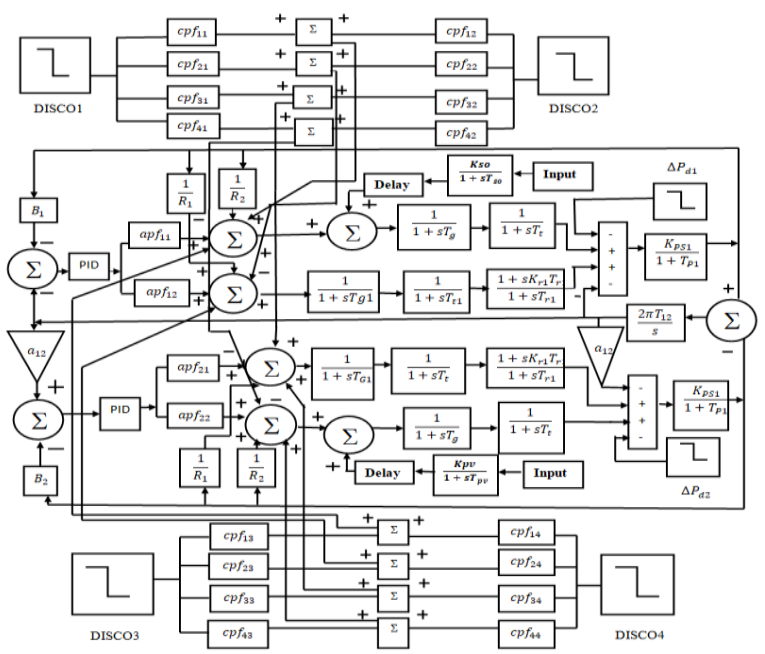

Fig. 4 Two area power system under deregulation

\section{SOLAR FIELD}

\subsection{Solar Thermal Model}

In the nature, solar energy is available in the form of light. This energy can deliver a reliable power to the system which is clean energy. Solar power plants require large amount of areas in parabolic with collectors blending in unidirectional path for working fluid through pipes are mounted at focus of parabola for generation of heat. The power which will be exchangeable is in the form of steam, while working fluid is heated to higher temperatures ( 3930 C). The steam caused by the heat transfer equipment is to drive the shaft of turbine which generates the electrical power. High heat temperature is required for solar power tower, which is from the concentrated solar radiation focus on the heat exchanger. Large number of heliostats (sun-tracking mirrors) required for the system design and it reflects the incident sunlight in the heat exchanger. In the receiver solar thermal energy heats the water or other fluids attain the steam at higher temperature (up to $5600 \mathrm{C}$ ) to run the shaft for the electricity generation. The system efficiency is $13 \%$. The efficiency of collector and heat exchanger system is of $70 \%$ till date [6].

The solar thermal power industry is developing in the recent years around the world. The model of solar thermal power system transfer function will be

$$
G_{s t}(s)=\frac{K_{s t}}{1+T_{s t} s}
$$

In solar thermal model, $\mathrm{K}_{\mathrm{st}}$ stands for gain and $\mathrm{T}_{\mathrm{st}}$ denotes the time constant

\subsection{Solar Photovoltaic Model}

From the available resources in the nature like solar photovoltaic model, clear energy is produced in the present eco system. In the sunlight, energy present in the form of photons is absorbed and converted into the electrical energy using power electronic devices and semiconductors. With an increase in the demand, solar PV system is one of the main renewable energy sources which reduce the overall investment such as PV module, cables, man power, inverters, fitting and available fuel. By using semi-conductor device $\mathrm{dc} / \mathrm{ac}$ converter, in solar PV system the DC output is converted to $\mathrm{AC}$ and the maximum amount of output power of solar PV system depends on cell surface temperature and irradiance. The best performance of the PV system is expected at the V-P curve's peak point. To track the maximum power point where maximum output occurs can be calculated using different maximum power point tracker (MPPT) techniques as explained in [6]. For the given irradiance and cell surface temperature, the output power that varies is given as

$$
\mathrm{P}_{\mathrm{s}-\mathrm{pv}}=\eta s f\left[1-0.005\left(T_{a}+25\right)\right]
$$

where, $\quad \eta=P V$ array efficiency $(9-12 \%)$

$$
\begin{aligned}
& \mathrm{s}=\mathrm{PV} \text { array measured area }\left(4084 \mathrm{~m}^{2}\right) \\
& \mathrm{f}=\text { Solar radiation }\left(\mathrm{kW} / \mathrm{m}^{2}\right) \\
& T_{a}=\text { Ambience temperature in degree Celsius }
\end{aligned}
$$

In the above equation, the constraints like PV array efficiency, measured area, ambience temperature and solar radiation are constants.

In solar photovoltaic model, the transfer function is depicted as

$$
G_{s-p v}(s)=\frac{K_{s-p v}}{1+T_{s-p v} s}
$$

where Ks-pv and Ts-pv are gain and time constant of this model.

\section{DESIGN OF CONTROLLERS}

\subsection{PID Controller}

This controller is used in different industries as it is a favored feedback controller because of its robustness, simple structure and functionality [14]. The error $\mathrm{e}(\mathrm{t})$ is the difference of set point which is desired controlled variable and measured process variable. This controller converts the error signal into $\mathrm{u}(\mathrm{t})$ i.e., manipulated variable, which will be applied directly to the plant. The combination of proportional, integral and derivative actions gives the desired performances like reduction of steady-state error, improves dynamic response. The mathematical representation of PID controller will be

$$
G_{P I D}(s)=K_{P}+\frac{K_{I}}{s}+K_{D} s
$$

$K_{P}, K_{I}$ and $K_{D}$ represents the different gains such as proportional, integral and derivative. The basic block diagram of PID controller is shown below in Fig. 5. 


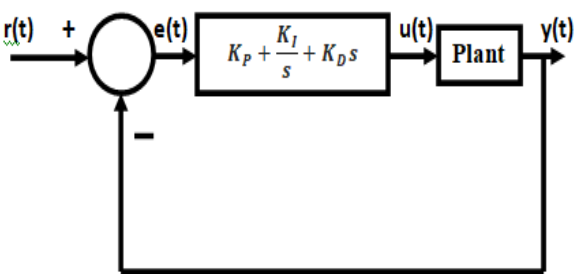

Fig. 5 Feedback control system with PID controller

\subsection{Cascaded PI-PD Controller}

The cascaded PI-PD controller is the combination of two processes such as inner process and outer process. Here, the output of inner process gives to the inner process. This controller mainly deals with the outer process disturbance reduction effect. By using this controller, we can observe the improved performance of the system [8]. The mathematical representation of PI-PD controller is

$$
G_{P I-P D}(s)=\left(K_{P 1}+\frac{K_{I}}{s}\right)\left(K_{P 2}+K_{D} s\right)
$$

The diagram of PI-PD controller is shown in Fig. 6.

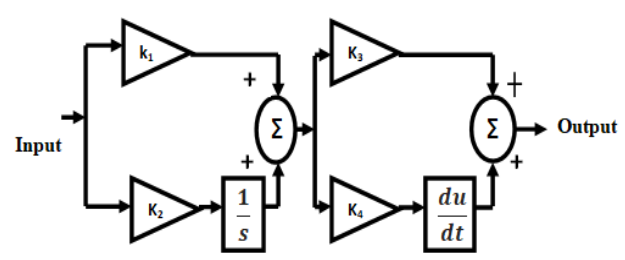

Fig. 6 Block Diagram of PI-PD controller

There are different tuning techniques for these controllers. Some of them are Ziegler-Nichols (ZN) method, Genetic Algorithm technique, Trial \& Error method, Particle swarm optimization Method (PSO). In this paper, Integral, PID, PI$\mathrm{PD}$ controllers are tuned using the PSO technique.

\subsection{Particle swarm optimization}

Particle swarm optimization (PSO) is an approach based on the population introduced in the year 1995 by Dr. Russel Eberhant and Dr. James Kennedy. This optimization technique is inspired by the behaviour of flock of birds and fish schooling. All the particles are flying through the search space for the solution. Each solution in the search space is called as particle and all these particles are updated using fitness function to optimize the problem, the direction of the particle depends upon the velocity and position of the particle in the problem space. This technique initially starts with random values of population; using these values the best values of the population is to be obtained. This is known as Pbest value. The Gbest value is the other best value to be obtained by particle swarm optimizer which is the best value in overall. By using these best values, at every time step the particles velocity and position are updated.

$v_{i}(t+1)=v_{i}(t) w+\left[c_{1} r_{1}\left[P_{\text {best }}^{i}-x_{i}(t)\right]+c_{2} r_{2}\left[G_{i}^{\text {best }}-\right.\right.$ $\left.x_{i}(t)\right]$

$$
x_{i}(t+1)=x_{i}(t)+v_{i}(t+1)
$$

The following equations represent the velocity and each particle position [6], [10]-[11].

where $v_{i}(t)$ is the $i^{\text {th }}$ particle velocity at time $t ; x_{i}(t)$ is the $i^{\text {th }}$ particle position at time $t ; c_{1}$ and $c_{2}$ are the learning factors and $r_{1}$ and $r_{2}$ are the random factors within the range of 0 to 1 . The basic steps for tuning different controllers are summarized as follows:

1. Evaluation of Pbest value of each particle.

2. Calculation of Gbest for the whole particle.

3. Update the velocity and position of each particle.

Objective function: In the designing of PID and PIPD controllers using PSO algorithm there are usually four indices for better performance. They are IAE, ISE, ITSE and ITAE. Here, we used ITAE as an objective function. Below equations represents the performance indices as follows

$$
\begin{aligned}
I A E & =\int_{0}^{T}|e(t)| d t \\
I S E & =\int_{0}^{T} e^{2}(t) d t \\
I T S E & =\int_{0}^{T} t \cdot e^{2}(t) d t \\
I T A E & =\int_{0}^{T} t \cdot|e(t)| d t
\end{aligned}
$$

Flowchart of the PSO algorithm [14] is shown in the Fig. 7.

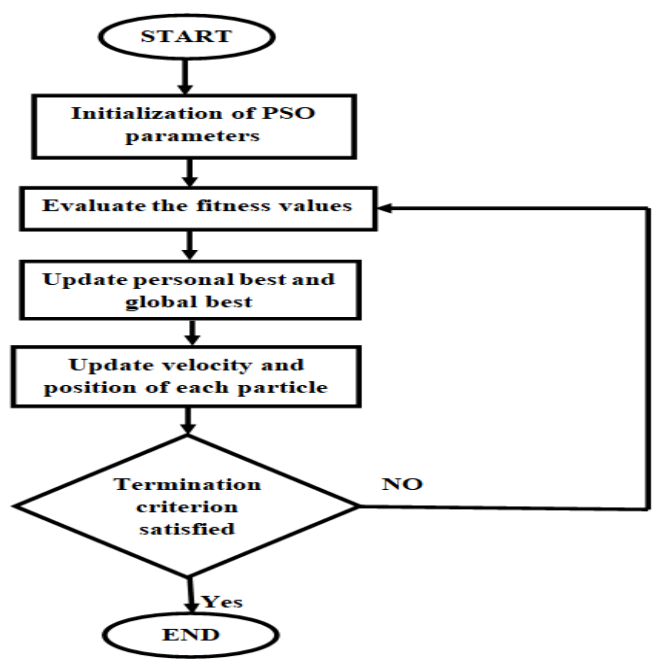

\subsection{Results and Discussion}

Base case: In this case, the GENCOs in each area participate equally in AGC. The GPM matrix is shown below

$$
G P M=\left[\begin{array}{ll}
0.5 & 0.5 \\
0.5 & 0.5
\end{array}\right]
$$

The load is demanded only by DISCO1 and DISCO2, whereas DISCO3, DISCO4 are not demanding any load from GENCO. Only in area-1 the changes in load will occur. Assume that load demands for DISCO1 and DISCO2 are $0.1 \mathrm{pu}$. The DPM matrix is shown below

$$
D P M=\left[\begin{array}{cccc}
0.5 & 0.5 & 0 & 0 \\
0.5 & 0.5 & 0 & 0 \\
0 & 0 & 0 & 0 \\
0 & 0 & 0 & 0
\end{array}\right]
$$

In a steady state condition, GENCO generation should be equal to DISCOs demand in contract. GENCOs desired generation expressed in terms of cpfs. 
Simulation is carried out for the system data given in Appendix. Controller gains are optimised using PSO algorithm. The variations of frequency and tie-line power for both areas are shown in Figs. 8-12. Comparison of settling times is provided in Tab. I.

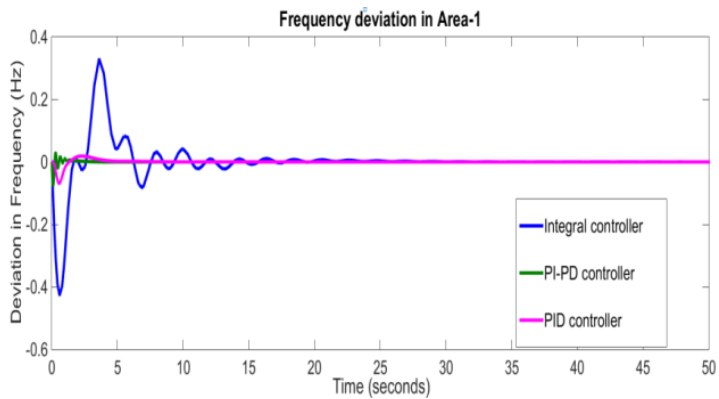

Fig.8: Frequency Deviation in area-1

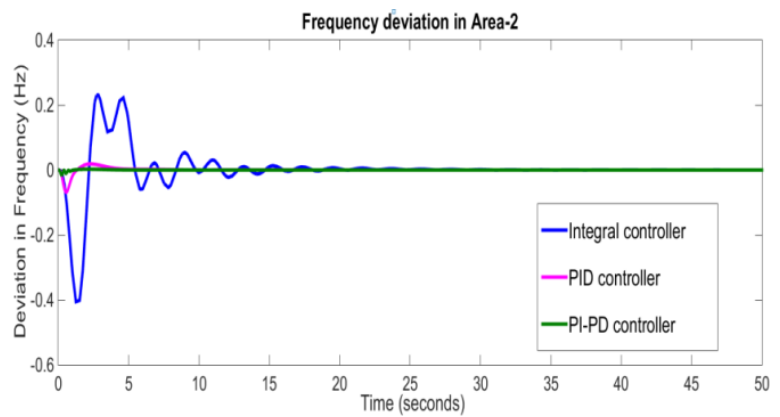

Fig. 9: Frequency Deviation in area-2

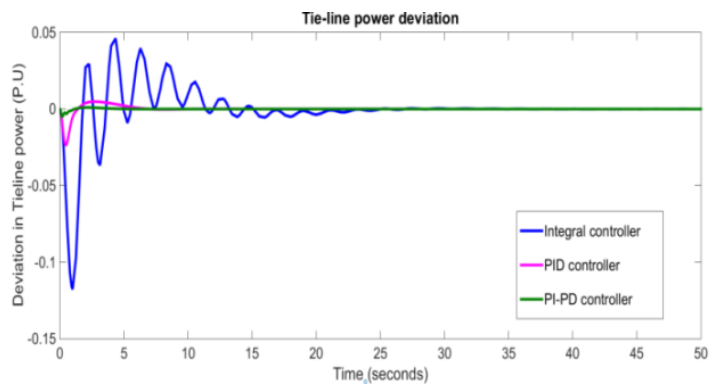

Fig. 10: Tie-line power deviations

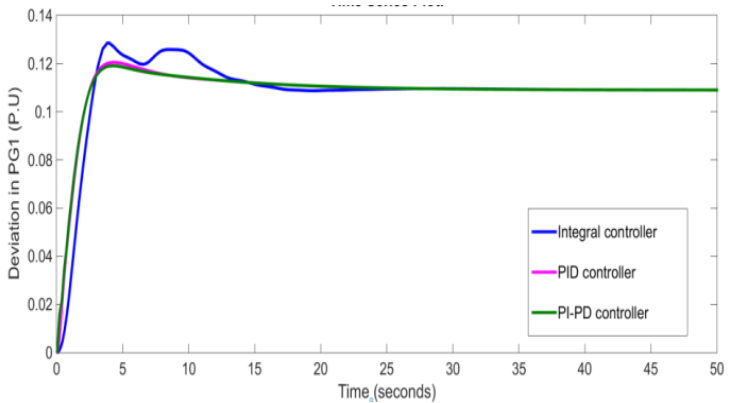

Fig. 11: Generation of GENCO1 for Base case

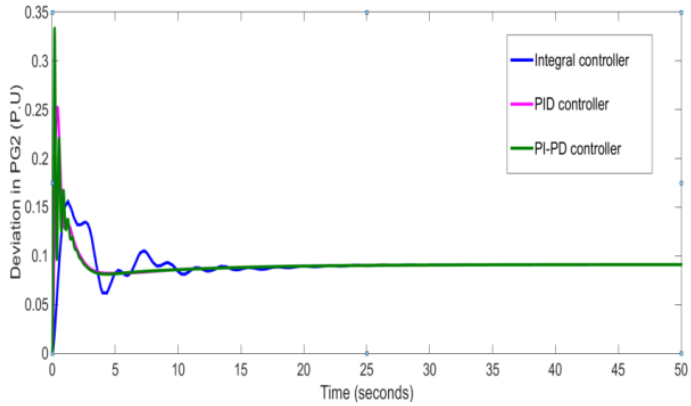

Fig. 12: Generation of GENCO2 for Base case

Tab. I: Comparison of settling times of different controllers in the base case

\begin{tabular}{|c|c|c|c|}
\hline & $\begin{array}{l}\text { Integral } \\
\text { controller }\end{array}$ & $\begin{array}{c}\text { PID } \\
\text { controller }\end{array}$ & $\begin{array}{c}\text { PI-PD } \\
\text { contr } \\
\text { oller }\end{array}$ \\
\hline$\Delta \mathbf{F}_{1}$ & $27 \mathrm{~s}$ & $6 \mathrm{~s}$ & $3 \mathrm{~s}$ \\
\hline$\Delta \mathbf{F}_{2}$ & $28.5 \mathrm{~s}$ & $10.5 \mathrm{~s}$ & $3.5 \mathrm{~s}$ \\
\hline $\begin{array}{l}\Delta \mathbf{P}_{\mathrm{T}} \\
\text { ie12 }\end{array}$ & 33 & 7 & $4.2 \mathrm{~s}$ \\
\hline
\end{tabular}

\section{Bilateral transaction case}

In this case, the DISCOs are in contract to all GENCOs for power transaction. All DISCOs demand power at $0.1 \mathrm{pu} \mathrm{MW}$. In DPM matrix the GENCOs are expressed with the aid of $c p f s$ and it shows the DISCOs contract with GENCOs. The GPM matrix is given below.

$$
G P M=\left[\begin{array}{cc}
0.75 & 0.25 \\
0.5 & 0.5
\end{array}\right]
$$

The apf values affect the transient behaviour and not the steady state behaviour of system. The DPM matrix for this case will be

$$
D P M=\left[\begin{array}{cccc}
0.5 & 0.25 & 0 & 0.3 \\
0.2 & 0.25 & 0 & 0 \\
0 & 0.25 & 1 & 0.7 \\
0.3 & 0.25 & 0 & 0
\end{array}\right]
$$

The optimal controller gains are computed with the help of PSO algorithm. The variations of frequency and tie-line power for the two different areas are shown in Figs. 13-19. Comparison of settling times is provided in Tab. II. 


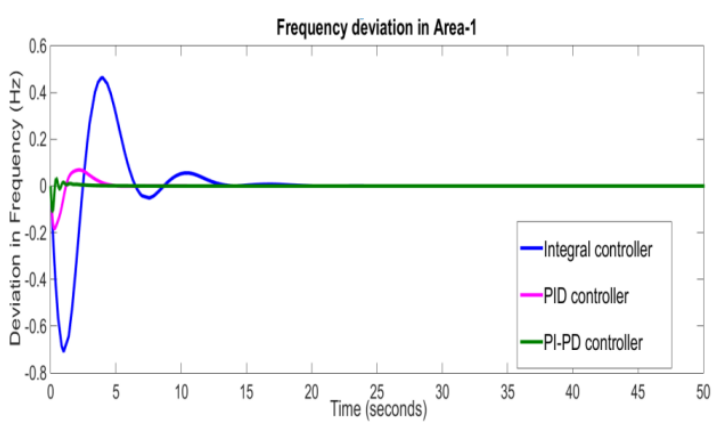

Fig. 13: Frequency deviation of Area-1

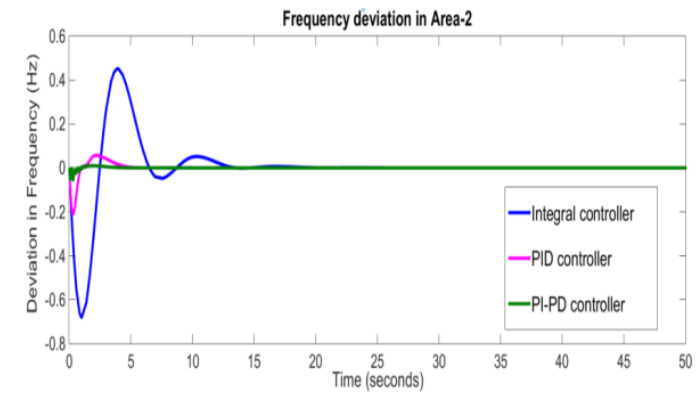

Fig. 14: Frequency deviation of Area-2

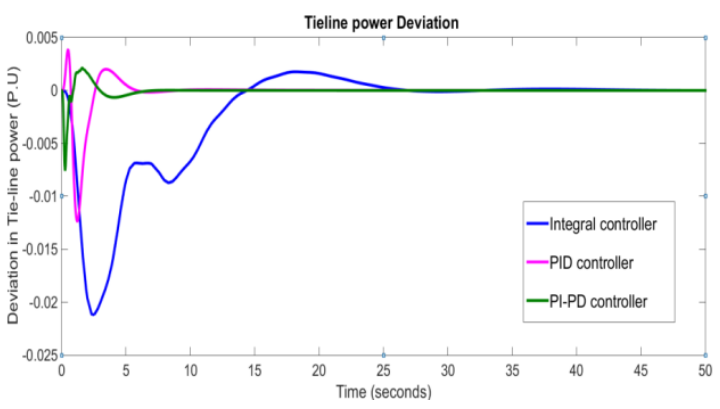

Fig. 15: Deviation in Tie line power

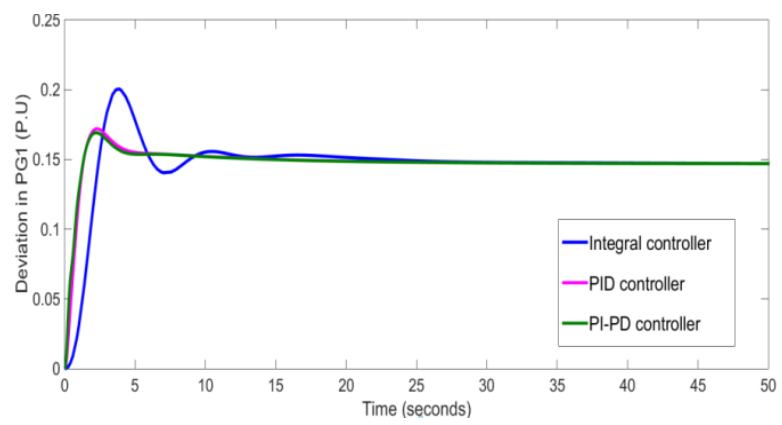

Fig.16: Generation of GENCO1 for bilateral transaction case

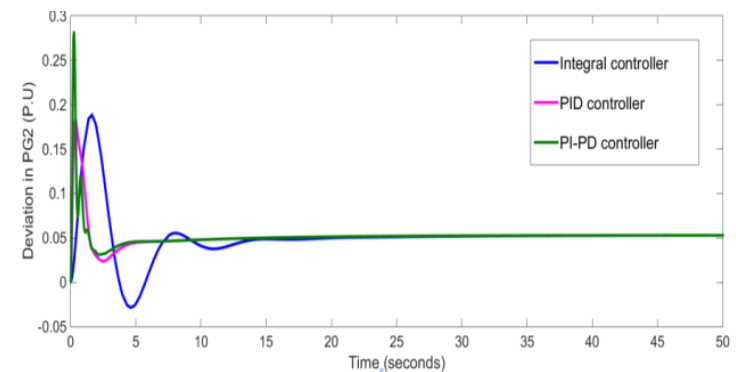

Fig. 17: Generation of GENCO2 for bilateral transaction case

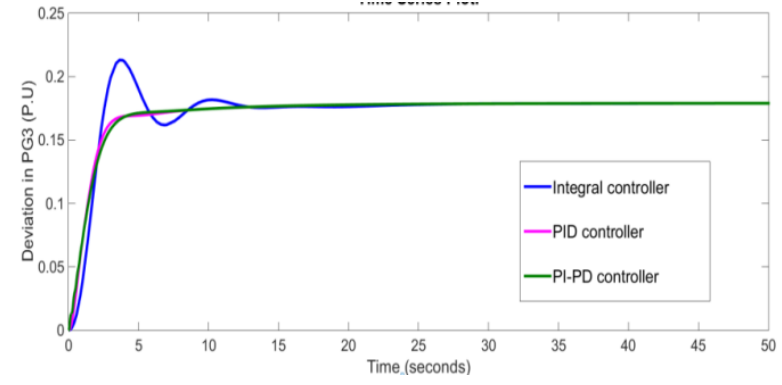

Fig. 18: Generation of GENCO3 for bilateral transaction case

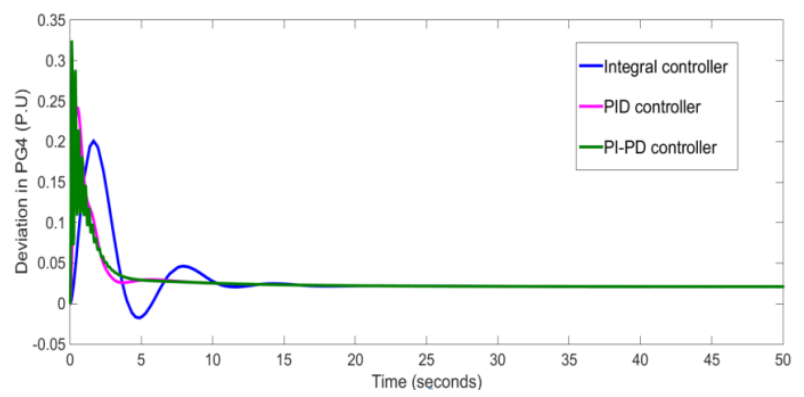

Fig. 19: Generation of GENCO4 for bilateral transaction case

Tab. II: Comparison of settling times of different controllers in the bilateral transaction case

\begin{tabular}{|r|c|c|c|}
\hline & $\begin{array}{c}\text { Integral } \\
\text { Controller }\end{array}$ & PID & PI-PD \\
& Controller & Controller \\
\hline$\Delta \mathbf{F}_{\mathbf{1}}$ & $20 \mathrm{~s}$ & $5 \mathrm{~s}$ & $4 \mathrm{~s}$ \\
\hline$\Delta \mathbf{F}_{\mathbf{2}}$ & $18 \mathrm{~s}$ & $5.8 \mathrm{~s}$ & $4.5 \mathrm{~s}$ \\
\hline$\Delta \mathbf{P}_{\text {Tie12 }}$ & $26 \mathrm{~s}$ & $9 \mathrm{~s}$ & $6.5 \mathrm{~s}$ \\
\hline
\end{tabular}

\section{Contract violation case}

In this case, more amount of power is demanded by the DISCO than specified by contract. GENCO supplies more amount of power to the DISCOs at same area. Here, considering DISCO1 demands that $0.1 \mathrm{pu}$ MW of extra power, this additional amount of power reflects only in the local area and its load is represented below.

$\triangle \mathrm{PL} 1=$ DISCO1 load $(0.1)+$ DISCO2 load $(0.1)+0.1=0.3$ pu MW

Area-2 local load is same when compared to the previous case i.e., $0.2 \mathrm{pu}$ MW. DPM is also same as in the bilateral transaction case. The un-contracted DISCO1 load has mirrored effect in GENCO1 and GENCO2 generations. Frequency variations for both areas and tie-line power deviations are shown in Figs. 20-26. Comparison of settling times is provided in Tab. III for this case. 


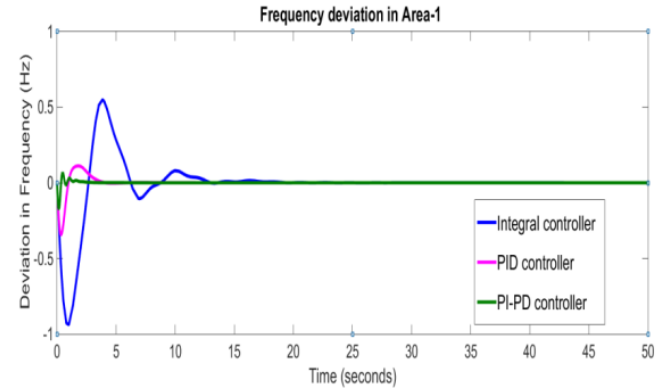

Fig. 20: Frequency deviation of Area-1

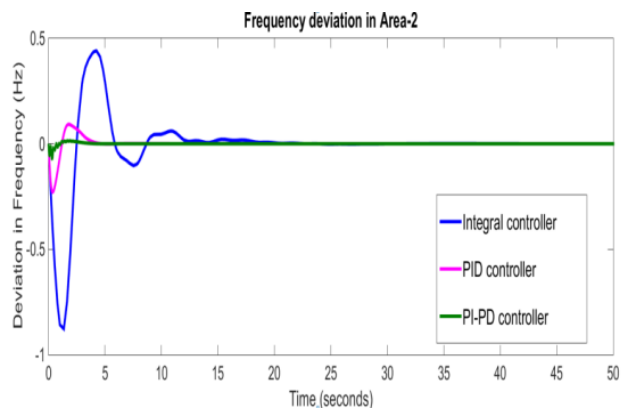

Fig. 21: Frequency deviation of Area-2

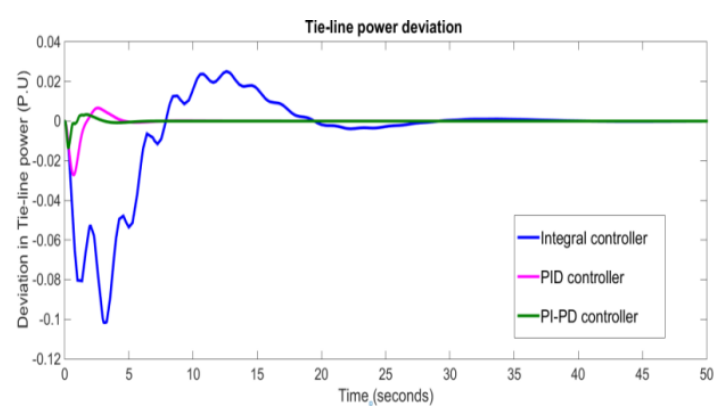

Fig. 22: Deviation in Tie line power

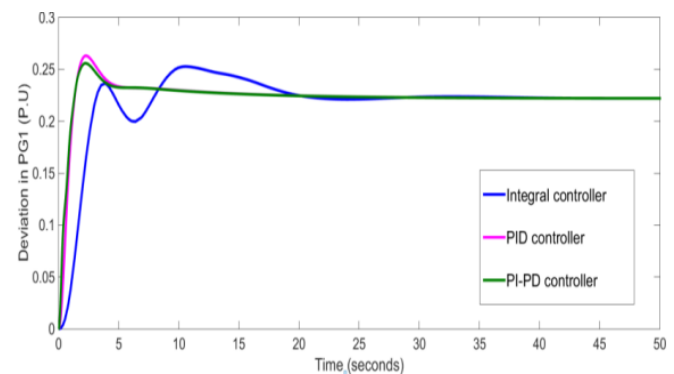

Fig. 23: Generation of GENCO1 for contract violation case

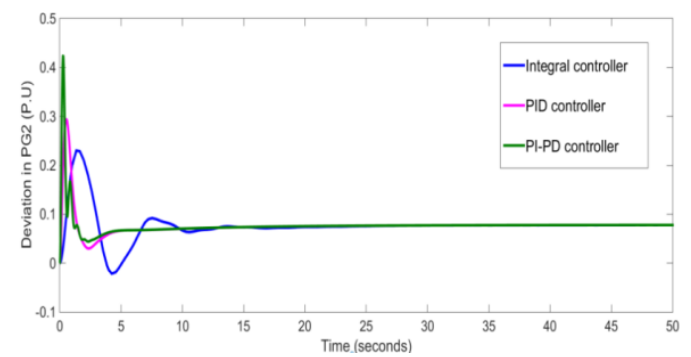

Fig. 24: Generation of GENCO2 for contract violation case

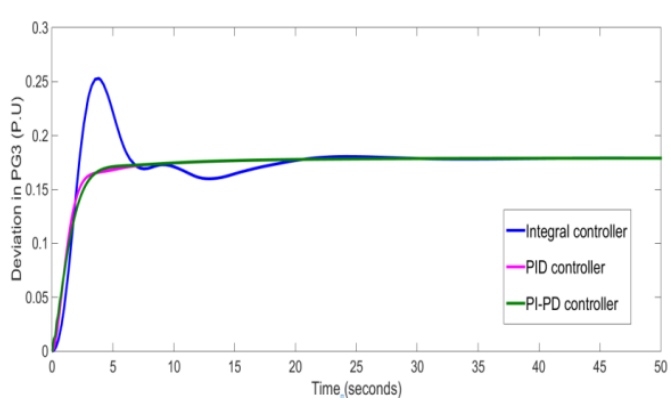

Fig. 25: Generation of GENCO3 for contract violation case

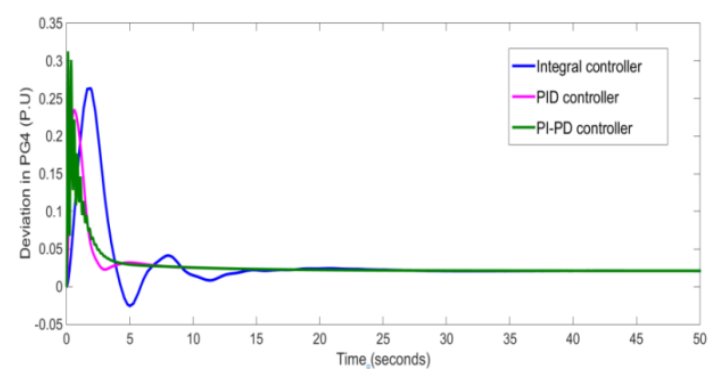

Fig. 26: Generation of GENCO4 for contract violation case

Tab. III: Comparison of settling times of different controllers in the contract violation case

\begin{tabular}{|c|c|c|c|}
\hline Controller & Integral & PID & PI-PD \\
\hline$\Delta \mathbf{F}_{1}$ & $21 \mathrm{~s}$ & $5 \mathrm{~s}$ & $3 \mathrm{~s}$ \\
\hline$\Delta \mathbf{F}_{\mathbf{2}}$ & $22 \mathrm{~s}$ & $5.5 \mathrm{~s}$ & $3.8 \mathrm{~s}$ \\
\hline$\Delta \mathbf{P}_{\text {Tie12 }}$ & $40 \mathrm{~s}$ & $8 \mathrm{~s}$ & $6.8 \mathrm{~s}$ \\
\hline
\end{tabular}

Tables IV-VI give steady state generations and load comparison for Integral, PID and PI-PD controllers respectively.

Tab IV: Steady State Generations and Loads for all cases with Integral Controller

\begin{tabular}{|c|c|c|c|}
\hline $\begin{array}{l}\text { GENCOs } \\
\text { Generation }\end{array}$ & Base case & $\begin{array}{c}\text { Bilateral } \\
\text { transaction } \\
\text { case }\end{array}$ & $\begin{array}{c}\text { Contract } \\
\text { violation case }\end{array}$ \\
\hline$\Delta P G_{1}(\mathrm{pu})$ & $\begin{array}{c}0.111 \\
(0.092 \mathrm{~T}+ \\
0.018 \mathrm{~S}) \\
\text { T- thermal } \\
\text { S- Solar }\end{array}$ & $\begin{array}{c}0.1471 \\
(0.1291 \mathrm{~T}+ \\
0.018 \mathrm{~S})\end{array}$ & $\begin{array}{c}0.2222 \\
(0.2042 \mathrm{~T}+ \\
0.018 \mathrm{~S})\end{array}$ \\
\hline$\Delta P G_{2}(\mathrm{pu})$ & 0.089 & 0.0529 & 0.0779 \\
\hline$\Delta P G_{3}(\mathrm{pu})$ & 0 & $\begin{array}{c}0.179 \\
(0.161 \mathrm{~T}+ \\
0.018 \mathrm{~S})\end{array}$ & $\begin{array}{c}0.179 \\
(0.161 \mathrm{~T}+ \\
0.018 \mathrm{~S})\end{array}$ \\
\hline$\Delta P G_{4}(\mathrm{pu})$ & 0 & 0.021 & 0.0210 \\
\hline & $\begin{array}{l}\Delta P L_{1}=0.2, \\
\Delta P L_{2}=0\end{array}$ & $\begin{aligned} \Delta P L_{1} & =0.2, \\
\Delta P L_{2} & =0.2\end{aligned}$ & $\begin{array}{c}\Delta P L_{1}=0.3, \\
\Delta P L_{2}=0.2 p u\end{array}$ \\
\hline
\end{tabular}


Tab V: Steady State Generations and Loads for all cases with PID Controller

\begin{tabular}{|c|c|c|c|}
\hline $\begin{array}{l}\text { GENCOs } \\
\text { Generation }\end{array}$ & Base case & $\begin{array}{l}\text { Bilateral } \\
\text { transaction } \\
\text { case }\end{array}$ & $\begin{array}{c}\text { Contract } \\
\text { violation case }\end{array}$ \\
\hline$\Delta \mathrm{PG}_{1}$ & $\begin{array}{c}0.109 \\
(0.091 \mathrm{~T}+ \\
0.018 \mathrm{~S})\end{array}$ & $\begin{array}{c}0.1471 \\
(0.1291 \mathrm{~T}+ \\
0.018 \mathrm{~S})\end{array}$ & $\begin{array}{c}0.2222 \\
(0.2042 \mathrm{~T}+ \\
0.018 \mathrm{~S})\end{array}$ \\
\hline$\Delta \mathrm{PG}_{2}$ & 0.0910 & 0.0529 & 0.0779 \\
\hline$\Delta \mathrm{PG}_{3}$ & 0 & $\begin{array}{c}0.179 \\
(0.161 \mathrm{~T}+ \\
0.018 \mathrm{~S})\end{array}$ & $\begin{array}{c}0.179 \\
(0.161 \mathrm{~T}+ \\
0.018 \mathrm{~S})\end{array}$ \\
\hline$\Delta \mathrm{PG}_{4}$ & 0 & 0.021 & 0.0210 \\
\hline & $\begin{array}{l}\Delta P L_{1}=0.2, \\
\Delta P L_{2}=0\end{array}$ & $\begin{array}{l}\Delta P L_{1}=0.2, \\
\Delta P L_{2}=0.2\end{array}$ & $\begin{array}{c}\Delta P L_{1}=0.3, \\
\Delta P L_{2}=0.2 p u\end{array}$ \\
\hline
\end{tabular}

Tab VI: Steady State Generations and Loads for all cases with PI-PD Controller

$\left.\begin{array}{|c|c|c|c|}\hline \begin{array}{c}\text { GENCOs } \\ \text { Generation }\end{array} & \text { Base case } & \begin{array}{c}\text { Bilateral } \\ \text { transaction } \\ \text { case }\end{array} & \begin{array}{c}\text { Contract } \\ \text { violation case }\end{array} \\ \hline \Delta P G_{1} & \begin{array}{c}0.109 \\ (0.091 \mathrm{~T}+ \\ 0.018 \mathrm{~S})\end{array} & \begin{array}{c}0.1471 \\ (0.1291 \mathrm{~T}+ \\ 0.018 \mathrm{~S})\end{array} & \begin{array}{c}0.2222 \\ (0.2042 \mathrm{~T}+ \\ 0.018 \mathrm{~S})\end{array} \\ \hline \Delta P G_{2} & 0.0910 & 0.0529 & 0.0779 \\ \hline \Delta P G_{3} & 0 & 0.179 & 0.179 \\ & & 0.161 \mathrm{~T}+ & (0.161 \mathrm{~T}+ \\ & 0 & 0.018 \mathrm{~S})\end{array}\right)$

Tables VII - IX give the tuning results of Integral, PID and PI-PD controllers using PSO method with ITAE performance index

Tab. VII: Gain values of Integral controller for the three cases

\begin{tabular}{|c|c|c|c|}
\hline Gain & Base & $\begin{array}{c}\text { Bilateral } \\
\text { Transaction } \\
\text { Case }\end{array}$ & $\begin{array}{c}\text { Contract } \\
\text { Violation } \\
\text { Case }\end{array}$ \\
\hline $\mathbf{K}_{\mathbf{1}}$ & 0.8408 & 0.4842 & 0.5144 \\
\hline $\mathbf{K}_{\mathbf{2}}$ & 0.2178 & 0.4711 & 0.4271 \\
\hline
\end{tabular}

Tab. VIII: Gain values of PID controller for the three cases

\begin{tabular}{|r|c|c|c|}
\hline Gain & $\begin{array}{c}\text { Base } \\
\text { Case }\end{array}$ & $\begin{array}{c}\text { Bilateral } \\
\text { Transaction } \\
\text { Case }\end{array}$ & $\begin{array}{c}\text { Contract } \\
\text { Violation } \\
\text { Case }\end{array}$ \\
\hline $\mathbf{K}_{\mathbf{1}}$ & 10.0000 & 10.0000 & 10.0000 \\
\hline $\mathbf{K}_{\mathbf{2}}$ & 10.0000 & 6.9739 & 7.3154 \\
\hline $\mathbf{K}_{\mathbf{3}}$ & 2.7897 & 6.4271 & 3.3630 \\
\hline $\mathbf{K}_{\mathbf{4}}$ & 7.1420 & 8.4200 & 8.2087 \\
\hline $\mathbf{K}_{\mathbf{5}}$ & 9.6780 & 9.8894 & 10.0000 \\
\hline $\mathbf{K}_{\mathbf{6}}$ & 5.1202 & 1.9874 & 1.9244 \\
\hline
\end{tabular}

Tab. IX: Gain values of PI-PD controller for the three cases

\begin{tabular}{|c|c|c|c|}
\hline Gain & $\begin{array}{c}\text { Base } \\
\text { Case }\end{array}$ & $\begin{array}{c}\text { Bilateral } \\
\text { Transaction } \\
\text { Case }\end{array}$ & $\begin{array}{c}\text { Contract } \\
\text { Violation } \\
\text { Case }\end{array}$ \\
\hline $\mathbf{K}_{\mathbf{1}}$ & 2.6686 & 5.1545 & 4.4054 \\
\hline $\mathbf{K}_{\mathbf{2}}$ & 7.5938 & 5.0793 & 5.5078 \\
\hline $\mathbf{K}_{\mathbf{3}}$ & 10.0000 & 10.0000 & 10.0000 \\
\hline $\mathbf{K}_{\mathbf{4}}$ & 4.6603 & 2.4553 & 2.2934 \\
\hline $\mathbf{K}_{\mathbf{5}}$ & 4.8372 & 5.7076 & 4.5245 \\
\hline $\mathbf{K}_{\mathbf{6}}$ & 5.8510 & 5.8046 & 6.3317 \\
\hline $\mathbf{K}_{\mathbf{7}}$ & 10.0000 & 10.0000 & 10.0000 \\
\hline $\mathbf{K}_{\mathbf{8}}$ & 4.5347 & 5.0783 & 5.8701 \\
\hline
\end{tabular}

In this system, controllers of different types are tuned by PSO algorithm with the performance indices of ITAE and the compared results are shown in the Figs.7-15. From these figures and Tables I-VI, it is observed that

1. For frequency and tie line power deviations, all the three controllers gave good steady state response with zero steady state errors

2. Compared to the Integral and PID controllers, PI-PD controller provided better transient performance with lesser settling times, overshoots and undershoots.

3. Steady state power deviations of Gencos including solar power are matching with load demand deviations in an area for all cases. Thus solar power generation reduces the burden on thermal power generation. 


\subsection{Conclusions}

Nowadays power systems are deregulated passing the benefits of deregulation to the customers. Also generations include conventional hydro, thermal as well as solar, wind and other renewable energy sources. Under this scenario a de-regulated two area reheat thermal system with solar thermal and solar photovoltaic units is considered.

AGC plays a vital role in the power system to maintain the frequency and tie line power to the nominal values by using secondary controllers. Choice of good secondary controller is very much necessary so that the AGC system has good transient and steady state responses. The secondary controllers considered are Integral, PID and PI-PD controllers. They are tuned by using PSO algorithm. From the above discussion, it can be concluded that the PI-PD controller gives greater transient response with zero steady state error compared with Integral and PID controllers. Hence on the whole PI-PD controller is the optimal one. This work may be continued to three or more areas with different generations as an extension.

\section{ACKNOWLEDGMENTS}

The authors profusely thank Siddhartha Academy of General and Technical Education, Vijayawada for providing the amenities to conduct this project.

\section{REFERENCES}

[1] A Textbook on Modern Power System Analysis by Hadi Sadat, Tata McGraw-Hill Edition 2002.

[2] Allen J. Wood., Bruce F. Wollenberg., A Textbook on Power Generation, Operation and Control, Second Edition, Wiley Student Edition.

[3] Hota, P. K., Mohanty, B. "Automatic generation control of multi source power generation under deregulated environment", International Journal of Electrical Power \& Energy Systems, 75, 205-214. doi:10.1016/j.ijepes.2015.09.003.

[4] Manoj Kumar Debnath, Sayantan Sinha, Ranjan Kumar Malli,“ Automatic Generation Control Including Solar Thermal Power Generation with Fuzzy-PID Controller with Derivative Filter", International Journal of Renewable Energy Research. Vol.8, No.1, March (2018).

\section{APPENDIX}

The system parameters are given below [4]

$\mathrm{F}=50 \mathrm{~Hz}, \operatorname{Tg} 1=0.08 \mathrm{~s}, \mathrm{Tt} 1=0.3 \mathrm{~s}, \mathrm{Tt}=3 \mathrm{~s} ; \mathrm{Tg}=1.0 \mathrm{~s}, \operatorname{Tr} 1=10 \mathrm{~s}$, $\mathrm{Kr} 1=0.5 ; \quad \mathrm{Kp}=120 \mathrm{~Hz}$ pu $\mathrm{MW}$ pu $\mathrm{MW} / \mathrm{rad}, \mathrm{H}=5 \mathrm{~s}$;
[5] Donde V., Pai MA., Simulation and optimization in an AGC system after deregulation, IEEE Transaction on Power systems, Vol.16 (3), 2001.

[6] Gaurav D., Salma U, "PSO Based Automatic Generation Control of Multi-Area Power Systems with Renewable Energy Sources", International Journal of Electronics, Electrical and Computational System, ISSN 2348-117, Vol 7, Issue 3, March (2018).

[7] Sandeep Bhongade., Barjeev Tyagi., Gupta H. O., "Automatic Generation Control Scheme including PhotoVoltaic Generating System for Interconnected Power System ", iitk.ac.in.

[8] S.Reddy Chittimuru., Sarvesh.B., "A New Optimized PD-PI Controller using NSGA-II for Automatic generation control", International Journal of Advanced Research in Electrical, Electronics and Instrumentation Engineering, Volume. 6, Issue 7, July (2017).

[9] Zwe-Lee Gaing., "Particle swarm optimization Approach for optimum design of PID controller in AVR system", IEEE Transactions on energy conversion, volume 19 , no.2, June (2004).

[10] Jyothi V., Bharat Kumar P., "Tuning controller parameters and load frequency control of multi-area multi-source power system by Particle Swarm Optimization Technique", International Research Journal of Engineering and Technology (IRJET), Vol 2 Issue 08, Nov (2015)

[11] Zeynelgil H.L., Demiroren A., Sengor N.S., "The applicatiom of ANN technique to automatic generation control for multi area power system", Electrical power and energy systems 24, 345-354, (2002).

[12] Saiteja K.,. Krishnarayalu M.S., "Load Frequency Control of Two-Area Smart Grid", International Journal of Computer Applications, Vol.117 No.14, (0975 8887) May (2015).

[13] Deepa Sharma., Bipul Kumar., "PSO Optimized PID Controller for Load Frequency Control", Europea Journal of Advances in Engineering and Technology, 2(11), 43-48, 2015.

$\mathrm{D}=8.33 * 10^{\wedge}-3 \mathrm{pu} \mathrm{MW/Hz} ; \mathrm{Tp}=20 \mathrm{~s} ; \mathrm{T}=0.086 ; \mathrm{Ri}=2.4 \mathrm{~Hz} / \mathrm{pu}$ $\mathrm{MW} ; \mathrm{Bi}=0.425 \mathrm{pu} \mathrm{MW/Hz;} \mathrm{Kst=1.8,} \mathrm{Tst=1.8} \mathrm{s,} \mathrm{Ks-pv=1,} \mathrm{Ts-}$ $\mathrm{pv}=1.8 \mathrm{~s}$. 